\title{
A study to evaluate the pattern and types of treatment of tibial plateau fracture at BPKIHS Dharan
}

\author{
R Rijal ${ }^{1}$, BP Shrestha ${ }^{1}$, GP Khanal ${ }^{1}$, P Chaudhary ${ }^{1}$, SR Paneru ${ }^{1}$, RPS Kalawar ${ }^{1}$, P Rai ${ }^{2}$ \\ Department of Orthopedics ${ }^{1}$, School of Public Health and Community Medicine ${ }^{2}$ \\ B.P. Koirala Institute of Health Sciences, Dharan, Nepal
}

\begin{abstract}
Background: Tibial plateau fractures occur due to a combination of axial loading and varus/valgus forces leading to articular cartilage damage, mal-alignment and secondary osteoarthritis and functional loss. Objective: To know pattern and types of treatment of tibial plateau fractures and effect of fracture pattern on functional outcome. Method: We conducted prospective study over a period of one year. Fifty-three patients with tibial plateau fractures were presented during that period. Eighteen patients were excluded due to significant polytrauma and major limb injuries. Four patients did not give consent for the study. Thirty-one patients meeting the criteria were enrolled in the study. Two patients were lost during follow up. Remaining patients were evaluated at the end of one year. Data were recorded and analyzed using appropriate statistical methods. Result: Among 29 patients, 21 were male. Mean age was $35.07 \pm 11.96$ years. $55.2 \%$ had RTA followed by 31 percent fall injury. $65 \%$ were treated with open reduction and internal fixation with plating followed by AK pop cast, cannulated cancellous screw and ilizarov fixation. Bone grafting was done in 3 cases. Twenty-five patients had excellent, two had good, two had fair and no patients had poor result. Three patients (10\%) had complications. One had common peroneal nerve palsy, two had wound infections and no patient demonstrated early arthritic changes. Conclusion: Tibial plateau fractures treated with different modalities at our institute has been associated with excellent and good functional outcome at the end of short term follow up.
\end{abstract}

Key words: Tibial plateau, fracture

\footnotetext{
Address for correspondence

Dr. Raju Rijal

Additional Professor

Department of Orthopaedics

B.P. Koirala Institute of Health Sciences, Dharan

Email: raju.rijal@bpkihs.edu
} 


\section{Introduction}

Tibial plateau fractures represent around 1\% of fractures in adults. ${ }^{1}$ Lateral side split, depression are produced by valgus and axial compression forces whereas posteromedial fracture fragment has been caused by flexed knee with varus and internal rotation of medial femoral condyle. ${ }^{2-4}$ Tibial plateau fractures extending to metaphyseal region are produced by direct trauma produced by axial load and bending forces resulting in severe soft tissue injury and compartment syndrome. ${ }^{5,6}$ Unlike fall injury in elderly, motor vehicle accident produce fractures in young adults. ${ }^{7,8}$ Schatzker classification system is patho-anatomical classification which guides to management of patient and is popular among surgeons. ${ }^{9}, 10$ Proximal tibia can withstand significant deformities unlike hip and ankle fracture; on that basis tibial plateau fractures were mostly treated by conservative methods in controlled traction, cast bracing and functional bracing paper till 1980. With advent of improved external and internal fixation devices, most of the fractures were treated by operative fixation methods. ${ }^{11-13}$

There was significant improvement in treatment of complex tibial plateau fractures in which compartment syndrome, soft tissues loss, infection, secondary osteoarthritis, malunion and nonunion may be the problems. ${ }^{14}$ There has been advancement in treatment of depressed fractures with use of bone graft and calcium based void fillers. ${ }^{15,16}$ Hence controlled traction, cast bracing, external fixation devices, closed reduction and percutaneous screws, unilateral and bilateral locked plate fixation have been used in such fractures. Secondary osteoarthritis had been associated with $17-37 \%$ in complex tibial plateau fractures leading to significant functional loss ultimately landing to arthrodesis or knee arthroplasty. ${ }^{17-20}$

We prospectively conducted this study to assess the effect of these injuries on functional outcome.

\section{Methods}

We conducted this study from August 2012 to July 2013 at department of orthopedics, B.P. Koirala Institute of Health Sciences, Dharan, Nepal. Consecutive adult patients with tibial plateau fractures were included in the study. Patients with significant poly trauma, major limb injuries, and spine injuries were excluded from the study. Research committee and institutional ethical review committee of B.P. Koirala Institute of Health Sciences approved the study. Junior residents and consultant orthopedic surgeon evaluated patients at emergency and outpatient clinic of B.P. Koirala Institute of Health Sciences.

Plain anteroposterior and lateral view X-Ray of involved knee and proximal leg was done to evaluate fracture pattern. Computed 
tomography scans was done for complex fractures and magnetic resonance imaging was done for assessment of soft tissue injury. Fractures were classified according to Schatzker et al. ${ }^{21}$ Open fractures were graded according to Gustilo et al. ${ }^{22}$

Non-operative treatment on cast was selected for Schatzker type I fractures only. After six weeks on cast, non-weight bearing on axillary crutch was done till 12 weeks and then full weight bearing was started.

Pre-anesthetic checkup was done for patients who were scheduled for surgery. Percutaneous screws were used for lateral split fractures. Open reduction and internal fixation with unilateral buttress plate was used for unicondylar fracture whereas dual plate fixation was done for bicondylar fractures. Depressed fractures were elevated and bone graft was harvested from iliac crest. Midline incision was used for bicondylar fractures whereas unilateral approach was used for either medial or lateral condyle fractures. Open fractures were treated with wound debridement and lavage. Ring and simple fixators were used for stabilization of compound fractures. Soft tissue coverage was done with either vascularized muscle flaps or split skin grafts.

Postoperatively all patients received a third generation cephalosporin and aminoglycosides for 48 hours. Patients who had an open wound received antibiotic treatment for a minimum of five days. Wound inspection was done on $2^{\text {nd }}$ postoperative days and patient was discharged to evaluate again at 2 weeks for suture removal.

After discharge, all patients were followed-up regularly in the outpatient clinic for clinical and radiological assessment. Union was assessed at each follow up. Functional assessment was performed using Jensen's score system. ${ }^{13}$ At final follow-up, all radiographs were reviewed by the principle investigator for any degree of joint depression, loss of alignment and the presence of early osteoarthritis.

Pain was assessed using a visual analogue score (VAS) ranging from 0 to 10. Statistical analysis was conducted in an exploratory fashion. We employed SPSS IBM20 software for all analysis. Descriptive statistics are used to compare outcomes depending upon the type of fracture and interventions applied. Data are presented as means, medians, and proportions according to the underlying distribution.

\section{Results}

Total 53 patients with tibial plateau fractures were presented during that period. Twentyfour patients were excluded from the study due to polytruama (8), spine injuries (6), tibial shaft fracture (6), and femoral shaft fracture (2) and unwilling to participate in the study 
(2). Remaining 29 patients were included in the study and evaluated accordingly.

Among 29 patients, 21 were male. Mean age of the patients was $35.07 \pm 11.96$ years (1665yrs). Right side (18) was predominantly involved. Sixteen patients got injury due to road traffic accident, followed by fall in 9 patients and 4 patients had farm related injuries. Around fifty percent patients were having Schatzker Type IV, V and VI injuries.
Three patients had associated fibula fracture. Four patients had compound fracture.

Closed reduction and percutaneous screw fixation is done in ten percent of patients. Sixty five percent of patients were treated with buttress plate and screws. Most of the patients were treated with operative procedures and open reduction with buttress plating was done in 19 patients as shown in table 1.

Table 1: Showing treatment modalities for tibial plateau fracture

\begin{tabular}{|l|l|l|}
\hline \multicolumn{1}{|c|}{ Treatment modalities } & \multicolumn{1}{c|}{ Frequency } & \multicolumn{1}{c|}{ Percent } \\
\hline Above knee cast & 4 & 13.8 \\
\hline${ }^{*}$ CRIF CCS & 3 & 10.3 \\
\hline Hybrid Ilizarov fixator & 1 & 3.4 \\
\hline Ilizarov fixator & 1 & 3.4 \\
\hline${ }^{\#}$ ORIF CCS & 1 & 3.4 \\
\hline ORIF buttress plate & 19 & 65.5 \\
\hline Total & 29 & 100 \\
\hline
\end{tabular}

${ }^{*}$ CRIF -closed reduction internal fixation, CCS- cannulated cancellous screw

\#ORIF- open reduction internal fixation

One patient had associated human immunodeficiency virus infection in which no complication was observed. Two patients developed superficial infection on day 3 postoperatively in case of dual buttress plate fixation, which was managed by wound dressing and injectable antibiotics. No patient developed deep infection. One patient developed common peroneal nerve palsy post operatively. However, the patient recovered the palsy at 4 month of follow up period. No patient developed compartment syndrome.

Average time to union was 16 weeks. One patient had developed non-union and bone grafting was done. In two cases, bone grafting was done to elevate articular congruity. Two patients had varus tilting of 5 degrees and articular depression around 5 $\mathrm{mm}$. 
Functional outcome was assessed using Jensen's grading system, which is shown in the Table 2. No patients had poor outcome after the intervention. Majority of the patients (86.2\%) had excellent outcome.

Table 2: Showing functional outcome using Jensen's grading system $(n=29)$

\begin{tabular}{|l|l|l|l|l|}
\hline \multicolumn{1}{|c|}{ Schatzker type } & Excellent & \multicolumn{1}{c|}{ Good } & \multicolumn{1}{c|}{ Fair } & Poor \\
\hline I & 6 & 0 & 0 & 0 \\
\hline II & 5 & 0 & 0 & 0 \\
\hline III & 2 & 0 & 1 & 0 \\
\hline IV & 6 & 0 & 1 & 0 \\
\hline V & 6 & 1 & 0 & 0 \\
\hline VI & 0 & 1 & 0 & 0 \\
\hline Total & $25(86.2 \%)$ & $2(6.9 \%)$ & $2(6.9 \%)$ & 0 \\
\hline
\end{tabular}

\section{Discussion}

Tibial plateau fracture has been managed by many methods in the past because of lack of optimal standard management procedures. ${ }^{21}$ and because of complications it's been a challenging job to orthopedic surgeons. ${ }^{14}$

In our study sixty five percent patients were male and around 35 years of age, which is comparable to other studies. ${ }^{23}$ Sixteen patients had fractures due to road traffic accidents and high energy injuries correlating with higher grades of Schatzker classification. Fall from height and farm related injuries are also seen in 13 patients which points towards geographical and occupational hazards to farmers. ${ }^{17,12,24,25}$

In our study three patients had associated fibula fractures resulting in more displaced tibial plateau fractures as mentioned in the literature absence of fibular head support may lead to displacement. ${ }^{26,27}$

In our study $13 \%$ percent patients were treated non-operatively, due to undisplaced fractures, poor medical conditions and refusal to surgery. They were managed with above knee cast and early active range of motion exercise; outcome is comparable to other studies. ${ }^{17-25}$

In our study four patients had compound fractures resulting from high velocity injury for which external fixator and llizarov fixation were used which resulted into longer duration of pin tract care and hospital visits and economical and functional loss to patients. ${ }^{23}$, 28

In our study majority of the patients were treated with open reduction and buttress plate fixation, due to complex and displaced 
fracture patterns that is correlated with other studies. ${ }^{28,29}$ In our study two patients (10\%) developed postoperative infections in dual plate fixation group, which was managed by wound dressing, culture and injectable antibiotics. Infection rates in dual plate fixation range between 0 and $87.5 \%$ in the literature. ${ }^{23,28-30}$

Compartment syndrome has been associated with complex tibial plateau fractures, which have been reported to be $9-23 \%$ in the literature. In our study there wasn't any case of compartment syndrome. In our study one patient developed postoperative common peroneal nerve palsy which recovered at 4 months of injury. ${ }^{11,24,27,29}$

In our study fractures union was at an average of 16 weeks of duration and one patient of Schatzker type VI developed nonunion, which was treated with bone grafting and non union is very rare as reported in the literature. ${ }^{26,28,30}$ Bone grafting was done in two cases to elevate the depressed fragments to achieve anatomical joint reduction and to prevent early osteoarthritis. ${ }^{25}$ Varus deformity around five degrees were seen in 6.9 percent of patients which are comparable to literature and did not require any intervention..$^{20,23}$

Jensen's clinical score was excellent in 25 cases; good in 2 cases and fair in 2 cases, which show early results in our center, is comparable to other study. ${ }^{12,13,28,30}$ No patient developed early secondary osteoarthritis. This could be due to very early follow up.

Less number of sample size and only one year of follow up are our limitations in this study. Best results were seen in minimally displaced unicondylar fractures and worst in bicondylar and diaphyseal metaphyseal dissociation cases.

\section{Conclusion}

Tibial plateau fractures remain important cause of morbidity and treatment goal should be anatomical reduction, stable fixation and early joint motion to prevent stiffness and reduction of complications. Functional outcome is directly related to joint reduction and severity of injury and higher grades of fractures. Tibial plateau fractures treated with different modalities at our institute has been associated with excellent and good functional outcome at the end of short term follow up.

\section{References}

1. Moore TM, Patzakis MJ, Harvey JP. Tibial plateau fractures: definition, demographics, treatment rationale, and long-term results of closed traction management or operative reduction. $\mathrm{J}$ Orthop Trauma 1987; 1(2): 97-119.

2. Lachiewicz PF, Funcik T. Factors influencing the results of open reduction and internal fixation of tibial plateau 
fractures. Clin Orthop Relat Res 1990 ;259: 210-215.

3. Chin TY, Bardana D, Bailey M, et al. Functional outcome of tibial plateau fractures treated with the fine-wire fixator. Injury 2005; 36(12): 1467-1475.

4. Scotland T, Wardlaw D. The use of castbracing as treatment for fractures of the tibial plateau. J Bone Joint Surg Br 1981; 63B (4):575-578.

5. Shah SN, Karunakar MA. Early wound complications after operative treatment of high energy tibial plateau fractures through two incisions. Bull NYU Hosp Jt Dis 2007; 65(2): 115-119.

6. Subasi M, Kapukaya A, Arslan H, et al. Outcome of open comminuted tibial plateau fractures treated using an external fixator. J Orthop Sci 2007; 12(4): 347-353.

7. Bajammal SS, Zlowodzki M, Lelwica A, et al. The use of calcium phosphate bone cement in fracture treatment. A metaanalysis of randomized trials. $J$ Bone Joint Surg Am 2008; 90(6): 1186-1196.

8. Lubowitz JH, Elson WS, Guttmann D. Part I: Arthroscopic management of tibial plateau fractures. Arthroscopy 2004; 20(10): 1063-1070.

9. Prasad N, Murray JM, Kumar D, et al. Insufficiency fracture of the tibial plateau: an often missed diagnosis. Acta Orthop Belg 2006; 72(5): 587-591.
10. Rademakers MV, Kerkhoffs GM, Sierevelt IN, et al. Operative treatment of 109 tibial plateau fractures: five- to 27-year followup results. J Orthop Trauma 2007; 21(1):5-10.

11. Apley AG. Fractures of the lateral tibial condyle treated by skeletal traction and early mobilisation; a review of sixty cases with special reference to the long-term results. J Bone Joint Surg Br 1956; 38-B: 699-708.

12. DeCoster TA, Nepola JV, el-Khoury GY. Cast brace treatment of proximal tibia fractures. A ten-year follow-up study. Clin Orthop Relat Res 1988; 196-204.

13. Jensen DB, Rude C, Duus B, et al. Tibial plateau fractures. A comparison of conservative and surgical treatment. $\mathrm{J}$ Bone Joint Surg Br 1990; 72:49-52.

14. Papagelopoulos PJ, Partsinevelos AA, Themistocleous GS, et al. Complications after tibia plateau fracture surgery. Injury 2006; 37:475-484.

15. Simpson D, Keating JF. Outcome of tibial plateau fractures managed with calcium phosphate cement. Injury 2004; 35:913918.

16. $\mathrm{Yu} \mathrm{B}, \mathrm{Han} \mathrm{K}, \mathrm{Ma} \mathrm{H}$ et al. Treatment of tibial plateau fractures with high strength injectable calcium sulphate. Int Orthop 2009; 33(4):1127-1133. 
17. Honkonen SE. Degenerative arthritis after tibial plateau fractures. J Orthop Trauma 1995; 9:273-277.

18. Lansinger O, Bergman B, Korner L, et al. Tibial condylar fractures. A twenty-year follow-up. J Bone Joint Surg Am 1986; 68:13-19.

19. Gosling T, Schandelmaier P, Muller M, et al. Single lateral locked screw plating of bicondylar tibial plateau fractures. Clin Orthop Relat Res 2005; 439:207-214.

20. Rasmussen PS. Tibial condylar fractures. Impairment of knee joint stability as an indication for surgical treatment. J Bone Joint Surg Am 1973; 55:1331-1350.

21. Schatzker J, McBroom R, Bruce D. The tibial plateau fracture. The Toronto experience 1968-1975. Clin Orthop Relat Res 1979; 94-104.

22. Gustilo RB, Mendoza RM, Williams DN. Problems in the management of type III (severe) open fractures: a new classification of type III open fractures. J Trauma 1984; 24:742-746.

23. Gaudinez RF, Mallik AR, Szporn M. Hybrid external fixation of comminuted tibial plateau fractures. Clin Orthop Relat Res 1996; 203-210.

24. The Canadian Orthopaedic Trauma Society Open reduction and internal fixation compared with circular fixator application for bicondylar tibial plateau fractures. Results of a multicenter, prospective, randomized clinical trial. $\mathrm{J}$ Bone Joint Surg Am 2006; 88:2613-2623. 25. Barei DP, Nork SE, Mills WJ, et al. Functional outcomes of severe bicondylar tibial plateau fractures treated with dual incisions and medial and lateral plates. $\mathrm{J}$ Bone Joint Surg Am 2006; 88:1713-1721.

26. Barei DP, Nork SE, Mills WJ, et al. Complications associated with internal fixation of high-energy bicondylar tibial plateau fractures utilizing a two-incision technique. J Orthop Trauma 2004; 18:649-657.

27. Lee JA, Papadakis SA, Moon C, et al. Tibial plateau fractures treated with the less invasive stabilisation system. Int Orthop 2007; 31:415-418.

28. Ali AM, Burton M, Hashmi $M$, et al. Outcome of complex fractures of the tibial plateau treated with a beam-loading ring fixation system. J Bone Joint Surg $\mathrm{Br}$ 2003; 85:691-699.

29. Kumar A, Whittle AP. Treatment of complex (Schatzker type $\mathrm{VI}$ ) fractures of the tibial plateau with circular wire external fixation: retrospective case review. J Orthop Trauma 2000; 14:339344.

30. Koval KJ, Sanders R, Borrelli J, et al. Indirect reduction and percutaneous screw fixation of displaced tibial plateau fractures. J Orthop Trauma 1992; 6:340346. 